\title{
Phenotypic estimates and heritability values of Artemia franciscana
}

\author{
M M Shirdhankar ${ }^{1}$, C Thomas ${ }^{2}$ \& S K Barve ${ }^{1}$ \\ ${ }^{1}$ College of Fisheries, Shirgaon, Ratnagiri, Maharashtra, India \\ ${ }^{2}$ Central Marine Fisheries Research Institute, Ernakulam, Kerala, India
}

Correspondence: M M Shirdhankar, College of Fisheries, Shirgaon, Ratnagiri, Maharashtra 415 629, India. E-mail: mangeshshirdhankar @yahoo.com

\section{Abstract}

Artemia, in all stages of its life cycle, is suitable food for most diversified groups of aquatic animals. Although its size at different stages restricts its use as a food for some groups of fish, this problem can be overcome using selective breeding techniques. The formulation of any selective breeding programme calls for a proper understanding of the genetic architecture of the economically important traits of the population under study. Thus, heritability for certain important life history and reproductive traits was estimated in Artemia franciscana from the Great Salt Lake, Utah. In the present study, the sexwise heritability values for growth and reproduction traits were estimated using parent-offspring regression. The phenotypic parameters for the same traits are also recorded. The naupliar length was $487.0 \pm 2.0$ and $490.6 \pm 1.8 \mu \mathrm{m}$ for males and females, respectively, whereas the heritability values for naupliar length were $0.5851 \pm 0.2153$ and $0.3766 \pm 0.1899$ respectively. The length at 3 and 6 days of age were $1.87 \pm 0.03$ and $4.10 \pm 0.08 \mathrm{~mm}$, respectively, for males whereas $1.87 \pm 0.03$ and $4.30 \pm 0.08 \mathrm{~mm}$, respectively, for females. The heritability values for length at 3 and 6 days of age for males were $0.3272 \pm 0.3651$ and $0.4965 \pm 0.2466$, respectively, whereas the respective values for the females were $0.1167 \pm 0.3841$ and $0.0222 \pm 0.2971$. The estimates of length at first brood, pre-reproductive period and number of offspring in first brood were $10.09 \pm 0.23 \mathrm{~mm}, 16.00 \pm$ 0.23 days and $53.57 \pm 1.37$ days, respectively, whereas the heritability values for respective traits were $0.0403 \pm 0.1078,0.3234 \pm 0.2874$ and $0.3404 \pm 0.2202$.

Keywords: Artemia, heritability, parent-offspring regression, phenotypic estimates

\section{Introduction}

Heritability expresses the proportion of total variance that is attributable to the average effect of the genes. The importance of heritability in a breeding experiment lies in its predictive role expressing the reliability of phenotypic value as a guide to the breeding value. It is of immense use in making decisions regarding the type of selection methods that allow the greatest and/or most rapid improvement. There is an apparent lack of information on quantitative genetics aspects of Artemia although Artemia was described in the 18th century and has been extensively studied with respect to its life history and biology. Naupliar sizes of different Artemia strains have been studied by Claus, Benijits \& Sorgeloos (1977), Claus, Benjits, Vandeputte \& Gardner (1979) and Vanhaecke \& Sorgeloos (1980a). The effects of salinity and temperature of the external medium on the growth and adult body size are reported by many workers (Martin \& Wilbur 1921; Heath 1924; Weisz 1946; Reeve 1963; Sick 1976; Vanhaecke \& Sorgeloos 1980b; Wear \& Heslett 1986; Triantaphyllidis, Poulopoulou, Abatzopoulos, Perez \& Sorgeloos 1995; Triantaphyllidis, Criel, Abatzopoulos \& Sorgeloos 1997). Many reports are available on the sexual maturity of Artemia (Jensen 1918; Weisz 1946; Tobias, Sorgeloos, Roels \& Sharfstein 1980; Wear, Haslett \& Alexander 1986). However, there is a lack of information regarding heritability estimates in Artemia, except for that of Browne, Sallee, Grosch, Segreti \& Purser (1984) to separate out the genetic component of a number of traits in Artemia.

Thus, in the present study, an attempt was made to estimate the heritability of some of the quantitative traits in Artemia franciscana using the parent-offspring regression method. These heritability esti- 
mates are required for predicting the selection response and to formulate the selective breeding programmes to develop bidirectional selective breeding lines to produce the required sizes of Artemia nauplii as well as the required sizes of intermittent Artemia life cycle stages to the aquaculture industry as food for larval fish.

\section{Materials and methods}

Nauplii of Artemia franciscana (Kellogg 1906) hatched out of cysts from the Great Salt Lake, Utah, packed by San Francisco Bay Brand of Inve Aquaculture, USA (batch no. 425 G, 06345), formed the experimental material for the present investigation. The nauplii hatched from cysts were transferred to a 12-L plastic basin containing $4 \mathrm{~L}$ of $35 \mathrm{~g} \mathrm{~L}^{-1}$ seawater. Salinity was gradually raised to $90 \mathrm{~g} \mathrm{~L}^{-1}$ by adding filtered saturated brine, prepared by dissolving the crude salt in $35 \mathrm{~g} \mathrm{~L}^{-1}$ seawater. The reproductive output of $\mathrm{Ar}$ temia is optimal in this medium, i.e. $90 \mathrm{~g} \mathrm{~L}^{-1}$ (Bowen 1962; Browne 1980, 1982). Initially, nauplii were stocked at the rate of $20000 \mathrm{~L}^{-1}$ in $4 \mathrm{~L}$ of seawater as suggested by Dhont, Lavens \& Sorgeloos (1993). The volume was then progressively increased to $10 \mathrm{~L}$ on the 6 th day by adding $1 \mathrm{~L}$ of $90 \mathrm{~g} \mathrm{~L}^{-1}$ seawater every day. Artemia were fed using the third diet of MaedaMartinez, Hortencia, Obregon-Barboza \& Dumont (1995), with little modification (20 g baker's yeast $+0.5 \mathrm{~g}$ Spirulina powder $+1.8 \mathrm{~mL}$ cod liver oil). Every day, $10 \%$ water was siphoned out with faeces and uneaten food. After the basin was carefully cleaned by hand, water was replenished with $90 \mathrm{~g} \mathrm{~L}^{-1}$ brine solution. Salinity of the culture media was checked every day using a refractometer, and was maintained at $90 \mathrm{~g} \mathrm{~L}^{-1}$.

As soon as males started clasping the females to form pairs, 61 pairs were removed and each pair was then kept in a 200-mL bottle containing $90 \mathrm{~g} \mathrm{~L}^{-1}$ seawater. They were fed with the same food as before. The bottles were cleaned every other day after carefully removing the breeders along with the supernatant water. After cleaning, the animals were placed back into the original bottle along with the same water. Bottles were examined twice a day, in the morning and evening, for the release of nauplii during that period. Ten nauplii from each of the successfully bred pairs were maintained individually in a 50-mL bottle and fed with the same feed as mentioned above. On the 3rd, 6th and 9th days, the rearing bottles were cleaned and water was changed.
This was designated as F1 generation. After maturation males and females of the F1 generation were mated, and due care was taken to avoid inbreeding. Ten nauplii from successfully bred pairs of the F1 generation formed the F2 generation, and it was raised in a similar way as the F1 generation. The total numbers of individuals measured were 239 males and 255 females from the F1 generation and 223 males and 195 females from the F2 generation. Measurements of traits such as naupliar size (length), length at 3 days of age and length at 6 days of age were recorded for all the individuals of the F1 and F2 generations, while traits such as pre-reproductive period, length at first brood and number of offspring in first brood were also recorded only for the females in both the generations after mating.

Heritability of the traits was estimated from the regression of offspring on parent. Sire-son and damdaughter data were used for this purpose. The statistical model and computational formulae are as follows.

(1) Statistical model:

$$
Z_{i}=\beta X_{i}+e_{i}
$$

where $Z_{i}$ is the value of offspring of the ith sire, $X_{i}$ the observation of the ith sire, $\beta$ the regression $Z$ on $X$, and $e_{i}$ the error associated with $Z_{i}$.

(2) Computational formulas:

$$
\begin{aligned}
& \Sigma z^{2}=\Sigma Z^{2}-\frac{\left(\Sigma Z^{2}\right)}{N} \\
& \Sigma x^{2}=\Sigma X^{2}-\frac{\left(\Sigma X^{2}\right)}{N} \\
& \Sigma x z=\Sigma X Z-\frac{(\Sigma X)(\Sigma Z)}{N}
\end{aligned}
$$

where $N$ is the number of parent offspring,

$$
\begin{aligned}
\widehat{\operatorname{Cov}}_{X Y} & =\frac{\Sigma x z}{N-1} \\
b & =\frac{\widehat{\operatorname{Cov}}_{x z}}{\sigma_{X^{2}}}=\frac{\Sigma x z}{\Sigma x^{2}}
\end{aligned}
$$

(because $N-1$ is common to both numerator and denominator).

Heritability was estimated as below:

$$
\begin{aligned}
b_{\mathrm{op}} & =\frac{1 / 2 \operatorname{Cov}_{\mathrm{op}}}{V_{\mathrm{P}}}=1 / 2 h^{2} \\
h^{2} & =2 b_{\mathrm{op}} \\
h^{2} & =2 \widehat{\operatorname{Cov}}_{X Y} / \sigma_{X^{2}}=2 b
\end{aligned}
$$

The Standard error of heritability was calculated according to Klein, DeFries \& Finkbeiner (1973) using 
the following formula:

$$
\begin{aligned}
S^{2} b & =\frac{\Sigma z^{2}-\left((\Sigma x z)^{2} / \Sigma x^{2}\right)}{N-2} \\
\mathrm{SE}(b) & =\sqrt{\frac{S^{2} b}{\Sigma x^{2}}} \\
\mathrm{SE}\left(h^{2}\right) & =2 \mathrm{SE}(b)
\end{aligned}
$$

\section{Results and discussion}

\section{Phenotypic parameters}

Phenotypic parameters of $A$. franciscana are presented in Table 1. The length of the newly hatched nauplii (Instar-I) varied from 381.8 to $564.4 \mu \mathrm{m}$ in males and 398.4 to $572.7 \mu \mathrm{m}$ in females. The mean length of nauplii in the present study was $487.0 \pm 2.1 \mu \mathrm{m}$ in males and $490.6 \pm 1.8 \mu \mathrm{m}$ in females. There was no significant difference between the mean length of males and females $(P>0.05)$. These values are well within the range of naupliar sizes reported by Vanhaecke \& Sorgeloos (1980a) for A. franciscana. The mean naupliar lengths reported by them are 489 and $486 \mu \mathrm{m}$ in two samples of the population, e.g. GSL1 and GSL2 respectively. It can be noted from the values presented above that the size variation between sexes starts right at the naupliar phase itself. Females tended to be larger com- pared with males, and this difference in size between sexes increased with age. On the 3rd day of age, females were measuring $1.8649 \pm 0.03 \mathrm{~mm}$ compared with $1.8712 \pm 0.03 \mathrm{~mm}$ for males. The differences in length of males and females on the 3rd day of age were not significantly different $(P>0.05)$. The mean lengths on the 6th days of age in males and females were $4.10 \pm 0.08$ and $4.30 \pm 0.08 \mathrm{~mm}$, respectively, compared with a mean length of $3.22 \pm$ $0.61 \mathrm{~mm}$ reported by Tobias et al. (1980) in A. franciscana. Vanhaecke \& Sorgeloos (1980b) reported the average larval length at 7 days of age to be $3.16 \pm 0.17 \mathrm{~mm}$ for the San Francisco Bay strain and stated that the Great Salt Lake, Utah, strain showed $125 \%$ more growth (i.e. $3.95 \mathrm{~mm}$ ) than the San Francisco Bay strain. The mean lengths of combined sexes observed in the present study results are comparable with that of the Great Salt Lake strain. This is quite natural, since the same strain has been used in the present work. Mean length on the 6th day of age was not significantly different between males and females. In the present study, the length was $10.0888 \pm 0.0854 \mathrm{~mm}$ at 16.00 days age of females, whereas Tobias et al. (1980) have recorded lengths of $6.63 \pm 1.10$ (GSL harvest of 1966) and $6.25 \pm 1.43$ (GSL harvest of 1977) $\mathrm{mm}$ on the 15th day. They conducted their experiment in culture media with a salinity of $34.8 \mathrm{~g} \mathrm{~L}^{-1}$ and water temperatures between $22.9{ }^{\circ} \mathrm{C}$

Table 1 Phenotypic parameters of Artemia franciscana

\begin{tabular}{llcr}
\hline & & Mean values & \\
\cline { 3 - 4 } Sr. no & Traits & Male & Female \\
\hline 1 & Naupliar length $(\mu \mathrm{m})$ & $486.9912 \pm 2.1136$ & $490.5754 \pm 1.8157$ \\
2 & Length on 3 days of age $(\mathrm{mm})$ & $1.8649 \pm 0.0275$ & $1.8712 \pm 0.0270$ \\
3 & Length on 6 days of age $(\mathrm{mm})$ & $4.1005 \pm 0.0754$ & $4.2990 \pm 0.0793$ \\
4 & Length at first brood $(\mathrm{mm})$ & - & $10.0888 \pm 0.2259$ \\
5 & Pre-reproductive period (days) & - & $16.0000 \pm 0.2259$ \\
6 & Number of offspring in first brood & - & $53.5696 \pm 1.3675$ \\
\hline
\end{tabular}

Table 2 Heritability estimates for life and reproductive traits of Artemia franciscana

\begin{tabular}{llll}
\hline & & Heritability values & \\
\cline { 3 - 4 } Sr. no & Traits & Male & Female \\
\hline 1 & Naupliar length & $0.5851 \pm 0.2153$ & $0.3766 \pm 0.1899$ \\
2 & Length on 3 days of age & $0.3272 \pm 0.3651$ & $0.1167 \pm 0.3841$ \\
3 & Length on 6 days of age & $0.4965 \pm 0.2466$ & $0.0222 \pm 0.2971$ \\
4 & Length at first brood & - & $0.0403 \pm 0.1078$ \\
5 & Pre-reproductive period & - & $0.3234 \pm 0.2874$ \\
6 & Number of offspring in first brood & - & $0.3404 \pm 0.2202$ \\
\hline
\end{tabular}


and $29.3{ }^{\circ} \mathrm{C}$. In the present study, the salinity of the culture media was $90 \mathrm{~g} \mathrm{~L}^{-1}$, whereas the temperature ranged from $30{ }^{\circ} \mathrm{C}$ to $33{ }^{\circ} \mathrm{C}$. Wear \& Haslett (1986) have reported that $A$. franciscana grows rapidly at $32{ }^{\circ} \mathrm{C}$ and $26{ }^{\circ} \mathrm{C}$ compared with $8{ }^{\circ} \mathrm{C}$. In the present study, the temperatures were higher compared with those of Tobias et al. (1980), and this difference may partially explain the differing results. The total number of offspring in first brood $(53.5696 \pm 1.3675)$ is comparable to the results of Rahaman \& Rathinasamy (1997).

Heritability estimates for the traits under study are presented in Table 2. Heritability values for naupliar length were of moderate magnitude in both males and females. Similarly, heritability values of males for length on 3 days of age and length on 6 days of age were also of moderate magnitude, whereas in females heritability values for these traits were of low magnitude. Heritability values estimated for the reproductive traits of female length at first brood and number of offspring in first brood were moderately heritable, whereas the heritability value for pre-reproductive period was low.

Various reports on heritability estimates by regression of offspring on parent are available in aquatic animals such as in Salmo gairdneri (Kincaid 1972), Eurytemora herdmani (McLaren 1976), Oreochromis niloticus (Tave \& Smitherman 1980) and Cyprinus carpio (Brody, Wohlfarth, Hulata \& Moav 1981). However, there are no reports on heritability values in Artemia to compare with the results of the present study.

Heritability values estimated for different traits are of low-to-medium magnitudes. Shirdhankar \& Thomas (2003) have realized substantial genetic gains from a bidirectional selection for naupliar length in A. franciscana. Thus, the heritability values can be used to formulate a selective breeding programme to develop suitable heading lines, with the specific aim of decreasing or increasing the size of a particular stage of the life cycle of Artemia to produce feed for a specific group of aquatic animals.

\section{References}

Bowen S. (1962) The genetics of Artemia salina. I. The reproductive cycle. Biological Bulletin 122, 25-32.

Brody T., Wohlfarth G., Hulata G. \& Moav R. (1981) Application of electrophoretic genetic markers to fish breeding. IV. Assessment of breeding value of full sib families. Aquaculture 24, 175-186.

Browne R.A. (1980) Reproductive pattern and mode in brine shrimp. Ecology 61, 466-470.
Browne R.A. (1982) The costs of reproduction in brine shrimp. Ecology 63, 43-47.

Browne R.A., Sallee S.E., Grosch D.S., Segreti W.O. \& Purser S.M. (1984) Partitioning genetic and environmental components of reproduction and life span in Artemia. Ecology 65, 949-960.

Claus C., Benijits F. \& Sorgeloos P. (1977) Comparative study of different geographical strains of the brine shrimp Artemia salina. In: Fundamental and Applied Research on the Brine Shrimp Artemia Salina (L.) in Belgium. European Mariculture Society (ed. by E. Jaspers \& G. Persoone), pp. 91-105 Special Publication No. 2. 110 pp EMS Bredene, Belgium.

Claus C., Benjits F., Vandeputte X. \& Gardner W. (1979) The biochemical composition of the larvae of two strains of $\mathrm{Ar}$ temia salina (L.) reared on two different algal foods. Journal of Experimental Marine Biology and Ecology 36, 171-183.

Dhont J., Lavens P. \& Sorgeloos P. (1993) Preparation and use of Artemia as food for shrimp and prawn larvae. In: CRC Handbook of Mariculture: Crustacean Aquaculture, 2nd edn, Vol. 1 (ed. by J.V. McVey), pp. 61-93. CRC Press, Boca Raton, FL, USA.

Heath H. (1924) The external development of certain phyllopods. Journal of Morphology 38, 453-483.

Jensen A.C. (1918) Some observations on Artemia gracilis, the brine shrimp of Great Salt Lake. Biological Bulletin 34, 18-28.

Kellogg V.L. (1906) A new Artemia and its life conditions. Science 24, 594.

Kincaid H.L. (1972) A preliminary report on genetic aspects of 150-day family weights in hatchery rainbow trout. In: Proceeding of the 52nd Annual Conference Western Association State Game and Fish Commission, Portland, July 16-19, pp. 562-565.

Klein T.W., DeFries J.C. \& Finkbeiner C.T. (1973) Heritability and genetic correlation: standard errors of estimate and sample size. Behavior Genetics 3, 355-364.

Maeda-Martinez A.M., Obregon-Barboza H. \& Dumont H.J. (1995) Laboratory culture of fairy shrimps using baker's yeast as basic food in a flow through system. Hydrobiologia 298, 141-157.

Martin E.G. \& Wilbur B.C. (1921) Salt antagonism in Artemia. American Journal of Physiology 55, 290-291.

McLaren I.A. (1976) Inheritance of demographic and production parameters in the marine copepod Eurytemora herdmani. Biological Bulletin 151, 200-213.

Rahaman A. \& Rathinasamy A. (1997) Artemia culture using rice bran as feed. IndianJournal of Experimental Biology $\mathbf{3 5}$, 506-510.

Reeve M.R. (1963) Growth efficiency in Artemia under laboratory conditions. Biological Bulletin 125, 133-145.

Shirdhankar M.M. \& Thomas P.C. (2003) Response to bi-directional selection for naupliar length in Artemia fransciscana. Aquaculture Research 34, 535-542.

Sick L.V. (1976) Nutritional effect of five species of marine algae on the growth, development, and survival of the brine shrimp Artemia salina. Marine Biology 35, 69-78. 
Tave D. \& Smitherman R.O. (1980) Predicted response to selection for early growth in Tilapia nilotica. Transactions of the American Fisheries Society 109, 439-445.

Tobias W.J., Sorgeloos P., Roels O.A. \& Sharfstein B.A. (1980) International study of Artemia. XIII. A comparison of production data to 17 geographical strains of Artemia In st. croix Artificial upwelling-Mariculture system.. In: The Brine Shrimp Artemia, Vol. 3 (ed. by G. Persoone, P. Sorgeloos, O. Roels \& E. Jaspers), pp. 383-392. Universa Press, Wetteren, Belgium.

Triantaphyllidis G.V.K., Criel G.R.J., Abatzopoulos T.J. \& Sorgeloos P. (1997) International study on Artemia. LIII. Morphological study of Artemia with emphasis to old world strains. I. Bisexual populations. Hydrobiologia 357, 139-153.

Triantaphyllidis G.V.K., Poulopoulou T.J., Abatzopoulos C.A., Perez P. \& Sorgeloos P. (1995) International study on Artemia. XLIX. Salinity effect on survival, maturity, growth, biometrics, reproductive and lifespan characteristics of a bisexual and a parthanogenetic population of Artemia. Hydrobiologia 302, 215-227.
Vanhaecke P. \& Sorgeloos P. (1980a) International study on Artemia. IV. The biometrics of Artemia strains from different geographical origin. In: The Brine Shrimp Artemia, Vol. 3 (ed. by G. Persoone, P. Sorgeloos, O. Roels \& E. Jaspers), pp. 393-405. Universa Press, Wetteren, Belgium.

Vanhaecke P. \& Sorgeloos P. (1980b) International study on Artemia XIV. Growth and survival of Artemia larvae of different geographical origin in a standard culture test. Marine Ecology Progress Series 3, 303-307.

Wear R.G. \& Haslett S.J. (1986) Effects of temperature and salinity on the biology of Artemia fransiscana kellong from lake Grassmere, New Zealand. 1. Growth and mortality. Journal of Experimental Biology and Ecology 98, 153-166.

Wear R.G., Haslett S.J. \& Alexander N.L. (1986) Effects of temperature and salinity on the biology of Artemia fransiscana Kellong from lake Grassmere, New Zealand. 2. Maturation, Fecundity and generation times. Journal of Experimental Biology and Ecology 98, 167-183.

Weisz P.B. (1946) The space time pattern of segment formation in Artemia salina. Biological Bulletin 91, 119-140. 